\title{
Modeling Enhanced Diffusion Mass Transfer in Metals during Mechanical Alloying
}

\author{
Boris B. Khina ${ }^{1}$ and Grigoriy F. Lovshenko ${ }^{2}$ \\ ${ }^{1}$ Physico-Technical Institute, National Academy of Sciences of Belarus \\ ${ }^{2}$ Belorussian National Technical University \\ Minsk, Belarus
}

\section{Introduction}

The subject of this Chapter is an urgent cross-disciplinary problem relating to both Mass Transfer and Materials Science, namely enhanced, or abnormal diffusion mass transfer in solid metals and alloys under the action of periodic plastic deformation at near-room temperatures. This phenomenon takes place during the synthesis of advanced powder materials by mechanical alloying (MA) in binary and multi-component systems, which is known as a versatile means for producing far-from equilibrium phases/structures possessing unique physical and chemical properties such as supersaturated solid solutions and amorphous phases (Benjamin, 1992; Koch, 1992; Koch, 1998; Ma \& Atzmon, 1995; Bakker et al., 1995; El-Eskandarany, 2001; Suryanarayana, 2001; Suryanarayana, 2004; Zhang, 2004; Koch et al., 2010).

Along with MA, this phenomenon is relevant to other modern processes used for producing bulk nanocrystalline materials by intensive plastic deformation (IPD) such as multi-pass equal-channel angular pressing/extrusion (ECAP/ECAE) (Segal et al., 2010; Fukuda et al., 2002), repetitive cold rolling (often termed as accumulative roll bonding-ARB, or folding and rolling-F\&R) (Perepezko et al., 1998; Sauvage et al., 2007; Yang et al., 2009), twist extrusion (Beygelzimer et al., 2006) and high-pressure torsion (HPT) using the Bridgman anvils (X.Quelennec et al., 2010). It is responsible for the formation of metastable phases such as solid solutions with extended solubility limits during IPD, demixing of initial solid solutions or those forming in the course of processing, and is considered as an important stage leading to solid-state amorphization in the course of MA.

In these and similar situations, the apparent diffusion coefficients at a room temperature, which are estimated from experimental concentration profiles, can reach a value typical of a solid metal near the melting point, $\mathrm{D} \sim 10^{-8}-10^{-7} \mathrm{~cm}^{2} / \mathrm{s}$, and even higher.

Mechanical alloying (MA) was discovered by J.S.Benjamin in early 1970es as a means for producing nickel-base superalloys with dispersed fine oxide particles (Benjamin \& Volin, 1974). Later it was found that MA brings about the formation of non-equilibrium structures in many metal-base systems, such as supersaturated solid solutions, amorphous and quasicrystalline phases, nanograins etc., and it had acquired a wide use for the synthesis of novel metallic and ceramic materials. MA of powder mixtures is performed in attritors, vibratory and planetary mills and other comminuting devices where particle deformation occurs during incidental ball-powder-ball and ball-powder-wall collisions. An important 
advantage of MA is cost efficiency since the alloys are produced without furnaces and other high-temperature equipment while its main drawback is contamination of the final product because of wear of the balls and inner surface of a milling device.

On the first stage of MA, particle fracturing and cold welding over juvenile surfaces bring about the formation of composite particles, which contain interweaved lamellas of dissimilar metals (if both of the initial components are ductile) or inclusions of a brittle component in a matrix of a ductile metal. This substantially increases the contact area of the starting reactants. After that, within a certain milling time depending on the energy input to the comminuting device, which is characterized by the ball acceleration reaching $60-80 \mathrm{~g}$ in modern industrial-scale planetary mills (Boldyrev, 2006)), non-equilibrium phases are formed. These transformations occur due to plastic deformation of composite particles, which brings about generation of non-equilibrium defects in the metals and enhanced solidstate diffusion mass transfer. Hence, the latter is virtually the most important phenomenon responsible for metastable phase transformations during MA.

Despite vast experimental data accumulated in the area of MA, a deep understanding of the complex underlying physicochemical phenomena and, in particular, deformation-enhanced solid-state diffusion mass transfer, in still lacking. As outlined in (Boldyrev, 2006), this situation hinders a wider use of cost and energy efficient MA processes and the development of novel advanced materials and MA-based technologies for their production. Further development in this promising and fascinating area necessitates a new insight into the mechanisms of deformation-enhanced diffusion, which is impossible without elaboration of new physically grounded models and computer simulation. As a first step, it seems necessary to review the known viewpoints on this intricate phenomenon.

In this Chapter, analysis of the existing theories/concepts of solid-state diffusion mass transfer in metals during MA is performed and a new, self-consistent model is presented, which is based on the concept of generation of non-equilibrium point defects in metals during intensive periodic plastic deformation. Numerical calculations within the frame of the developed model are performed using real or independently estimated parameter values (Khina et al., 2004; Khina et al., 2005; Khina \& Formanek, 2006).

\section{Brief analysis of existing concepts}

Different models that are used in the area of MA can be divided into three large groups: mechanistic, atomistic and macrokinetic ones. The mechanistic models (Maurice \& Courtney, 1990; Magini \& Iasona, 1995; Urakaev \& Boldyrev, 2000a; Urakaev \& Boldyrev, 2000b; Chattopadhyay et al., 2001; Lovshenko \& Khina, 2005) consider the mechanics of ball motion and incidental ball-powder-ball and ball-powder-wall collisions in a milling device. The concept of elastic (Hertzian) collision is employed. This approach permits estimating the maximal pressure during collision, energy transferred to the powder, the collision time, strain and strain rate of the powder particles, local adiabatic heating and some other parameters, which can be used for assessing the physical conditions under which deformation-enhanced diffusion and metastable phase formation occur in the particles in the course of MA. This approach was used by the authors for evaluating the MA parameters for a vibratory mill of the in-house design (Lovshenko \& Khina, 2005). However, these and similar models all by itself cannot produce any information about the physics of defect formation, enhanced diffusion mass transfer and non-equilibrium structural and phase transformations in metals and alloys under mechanical deformation. 
Atomistic models employ molecular statics and molecular dynamics simulations (MDS) (Lund \& Schuh, 2004a; Lund \& Schuh, 2004b; Odunuga et al., 2005; Delogu \& Cocco, 2005). They permit studying ordering and disordering processes, atomic intermixing, i.e. diffusion over a small (nanometric) scale and non-equilibrium phase transitions, e.g., amorphization, in crystalline solids under the influence of an external mechanical force (the so-called "mechanically driven alloys"). In MDS, considered are individual nanosized particles or thin films. However, these models are poorly linked both to external conditions, i.e. the processing regimes in a milling device, and to macroscopic physicochemical parameters that are measured, directly or indirectly, basing on the experimental results or are known in literature, such as diffusion coefficients. Besides, it should be born in mind that since MDS is typically performed over a relatively small-size matrix using periodic boundary conditions, generalization of the obtained results to a macroscopic scale is not always well justified and hence one should use them with caution when interpreting the experimental data on MA.

Macrokinetic models of MA occupy a position in between the mechanistic and atomistic approaches and are based on the results of the latter. They can give important information on the physicochemical mechanisms of non-equilibrium phase and structure formation and deformation-enhanced diffusion during MA, which is necessary for optimization of existing and development of novel MA-based technologies and MA-produced materials, link the mechanical parameters of MA to the transformation kinetics in an individual particle, and bridge the existing gap between the two aforesaid approaches. However, such models are least developed as compared with the mechanistic and atomistic ones, which is connected with the problem complexity. Up to now, two basic concepts are know.

Most elaborated is a semi-quantitative concept according to which the dominated role in the mechanochemical synthesis belongs to fracturing of initial reactant particles with the formation of juvenile surfaces during collisions in a comminuting device (Butyagin, 2000; Delogu \& Cocco, 2000; Delogu et al., 2003; Butyagin \& Streletskii, 2005). In this case, crystal disordering occurs in surface layers whose thickness is several lattice periods. In the contact of juvenile surfaces of dissimilar particles during collision, co-shear under pressure brings about the so-called "reactive intermixing" on the atomic level, which leads to the formation of a product (i.e. chemical compound) interlayer. Here, the most important factor is a portion of the collision energy transferred to the reactant particles per unit contact surface area, which was estimated in the above cited works. In our view, such a mechanism of interaction is typical of mechanical activation and mechanochemical synthesis in inorganic systems where the reactant particles (salts, oxides, carbonates etc.) are hard and brittle, and the dominating process during collisions is brittle fracture over cleavage planes.

In binary and multicomponent metal-base systems, unlike brittle inorganic substances, the main process during mechanical alloying is plastic deformation of composite (lamellar) particles formed on earlier stages due to fracturing and cold welding of initial pure metal particles. The formation of solid solutions, metastable (e.g., amorphous) and stable (e.g., intermetallic) phases in the course of MA is impossible without intermixing on the atomic level in the vicinity of interfaces in composite particles (boundaries of lamellas of pure metals), i.e. without diffusion. Thus, the second macrokinetic concept of MA outlines the role of deformation-induced solid-state diffusion mass transfer (Schultz et al., 1989; Lu \& Zhang, 1999; Zhang \& Ying, 2001; Ma, 2003), which is less developed in comparison with the "reactive intermixing" model referring to the area of inorganic mechanochemistry.

It should be noted that the phenomenon of abnormal (enhanced) non-equilibrium diffusion mass transfer under intensive plastic deformation (IPD) was experimentally observed in 
bulk metals at different regimes of loading, from ordinary mechanical impact to shock-wave (explosion) processing in a wide rage of temperature, strain $\varepsilon$ and strain rate $\dot{\varepsilon}$ (Larikov et al., 1975; Gertsriken et al., 1983; Arsenyuk et al., 2001a; Arsenyuk et al., 2001b; Gertsriken et al., 1994; Gertsriken et al., 2001), and at ultrasound processing (Kulemin, 1978). The apparent diffusion coefficient, which is calculated from the time dependence of the diffusion zone width, was found to increase by many orders of magnitude and approach a value typical of a metal in the pre-melting state. Extensive experimental investigation performed in the above cited works using a wide range of techniques such are autoradiography, X-ray analysis, Mossbauer spectroscopy and other methods have demonstrated that IPD of bimetallic samples (a metal specimen clad with another metal) in binary substitutional systems brings about the formation of supersaturated solid solutions. The penetration depth of atoms from a surface layer into the bulk material reaches several hundred microns and the concentration of alloying element can be large: $18 \% \mathrm{Al}$ in copper and up to $10 \% \mathrm{Cu}$ in aluminum in the $\mathrm{Cu}-\mathrm{Al}$ bimetallic couple at $300 \mathrm{~K}$ and $\dot{\varepsilon}=120 \mathrm{~s}^{-1}$ (Gertsriken et al., 1994).

However, an adequate explanation of the enhanced non-equilibrium diffusion mass transfer phenomenon in crystalline solids under IPD has not been developed so far. Moreover, the very role of diffusion in MA is a subject of keen debates in literature: in particular, a series of mutually contradicting papers was published in journal "Metal Science and Heat Treatment" (Farber, 2002; Skakov, 2004; Gapontsev \& Koloskov, 2007; Skakov, 2007; Shtremel', 2002; Shtremel', 2004; Shtremel', 2007). In (Farber, 2002), the physical factors that could be responsible for the acceleration of solid-state diffusion, e.g., generation of nonequilibrium point defects during deformation, were described in detail on a qualitative level but no calculations nor even simple numerical estimates were given. Experimental data on the formation of supersaturated solid solutions at MA were reviewed in (Skakov, 2004; Skakov, 2007) and a qualitative hypothesis was presented. In (Gapontsev \& Koloskov, 2007), a model for enhanced diffusion is presented wherein the disclinations (i.e. triple grain junctions) act as sources and sinks of non-equilibrium vacancies during IPD thus giving rise to intensive diffusion fluxes of vacancies across grains, which, it turn, promote the diffusion of alloying atoms. On the other hand, in (M.A.Shtremel', 2002; M.A.Shtremel', 2004) simple numerical estimates based on the classical theories of diffusion and plastic deformation, which can not account for the process-specific factors acting in the conditions of MA, were used to support an opposite viewpoint that atomic diffusion plays an insignificant and even negative role in the formation of solid solutions and intermetallics during MA. It is speculated that the basic reason of alloying during IPD is not diffusion mass transfer but "mechanical intermixing of atoms" at shear deformation (Shtremel', 2004; Shtremel', 2007) but the physical meaning of this term is not explained; the author of the cited papers did not present any theories nor numerical estimates to support this concept. Different viewpoints on the role of atomic diffusion and deformation-generated point defects in the structure formation in alloys under IPD have been recently reviewed in (Lotkov et al., 2007).

As was noted earlier (Khina \& Froes, 1996), this situation is determined by insufficient theoretical knowledge of the physical mechanisms underlying the deformation-enhanced diffusion mass transfer during MA on the background of extensive experimental data accumulated in this area. Unfortunately, this statement is still valid now to a large extent. The absence of a comprehensive macrokinetic model is a constraint on the way of a further development of novel materials and technologies based on MA and other IPD techniques. In several theoretical works employing the macrokinetic approach, mathematical models of deformation-induced diffusion mass transfer during MA considered only diffusion along 
curved dislocation lines (the so-called dislocation-pipe diffusion) (Rabkin \& Estrin, 1998) or a change of geometry of an elementary diffusion couple in a composite (lamellar) particle because of deformation (Mahapatra et al., 1998); in the latter case, traditional diffusion equation (the Fick's law) was used. In these attempts, the role of deformation-generated point defects was not included. Besides, the whole processing time of powders in a milling device was considered as the time of diffusion (from $1 \mathrm{~h}$ in (Rabkin \& Estrin, 1998) to $50 \mathrm{~h}$ in (Mahapatra et al., 1998)) although it is known from mechanistic models that at MA the collision time, during which deformation-induced diffusion occurs, is substantially (by several orders of magnitude) shorter than intervals between collisions (Benjamin, 1992; Suryanarayana, 2001; Suryanarayana, 2004; Maurice \& Courtney, 1990; Chattopadhyay et al., 2001; Lovshenko \& Khina, 2005). In (Mahapatra et al., 1998), the numerical value of the main parameter, viz. volume diffusion coefficient, was taken at an elevated temperature, which was varied arbitrary (in the range $505-560 \mathrm{~K}$ for binary system $\mathrm{Cu}-\mathrm{Zn}$ and up to $825 \mathrm{~K}$ for system $\mathrm{Cu}-\mathrm{Ni}$ ) to attain agreement with experimental data. This is motivated by particle heating during ball-powder-ball collisions, although it is known that during a head-on collision, which provides maximal pressure, strain and strain rate of particles, a local temperature rise is small $(\sim 10 \mathrm{~K})$ for most of the milling devices, and the temperature quickly decreases to the background level due to high thermal conductivity of metals (Maurice \& Courtney, 1990; Lovshenko \& Khina, 2005). The main conclusion from modeling performed in (Mahapatra et al., 1998) is trivial: to achieve agreement between the calculations obtained using the Fickian equation and the experimental data on the alloying degree reached at a long processing time, the diffusion coefficient must have a value typical of that at a high temperature. This fact is known for many years: the effective (i.e. apparent) diffusion coefficient at IPD exceeds the equilibrium value at the processing temperature by several orders of magnitude.

There are several models of abnormal solid-state diffusion at shock loading of a bimetallic specimen, which are based on extended non-equilibrium thermodynamics (Sobolev, 1997; Buchbinder, 2003). Fast diffusion in metals caused by a propagating shock wave is described using the hyperbolic telegrapher equation, i.e. the equation of a decaying elastic wave. Within this concept, in the left-hand side of the Fickian diffusion equation, the second timederivative, $\partial^{2} \mathrm{C} / \partial \mathrm{t}^{2}$, is included along with term $\partial \mathrm{C} / \partial \mathrm{t}$, where $\mathrm{C}$ is concentration. This brings about a final propagation velocity of the concentration disturbance (Buchbinder, 2003). But in this approach, mass transfer is considered as occurring in a structureless continuum (a fluid), and a physical mechanism responsible for fast diffusion in a crystalline solid is not revealed. In (Bekrenev, 2002), a similar situation is analyzed by introducing a drift term into the right-hand side of the diffusion equation to describe the motion of solute atoms in the field of an external force. However, this term was not analyzed in detail.

Models for diffusion demixing of a solid solution or intermetallic compound in the course of MA have been developed (Gapontsev \& Koloskov, 2007; Gapontsev et al., 2000; Gapontsev et al., 2002; Gapontsev et al., 2003) which consider the formation of non-equilibrium vacancies in grain boundaries and their diffusion into grains. The vacancy flux directed into grains brings about an oppositely directed diffusion flux of solute atoms, which ultimately results in demixing of this stable or metastable phase. In its physical meaning, this model refers to a case when diffusion processes in a lamellar particle has already completed and a uniform product phase (metastable or equilibrium) has formed, and further milling brings about decomposition of the MA product. It should be noted that cyclic process of formation and decomposition of an amorphous or intermetallic phase was observed during prolonged 
ball milling in certain systems (El-Eskandarany et al., 1997; Courtney \& Lee, 2005). In these models, grain boundaries (Gapontsev et al., 2000; Gapontsev et al., 2002; Gapontsev et al., 2003) or disclinations (triple grain junctions) (Gapontsev \& Koloskov, 2007) can act as vacancy sources when the deformation proceeds via grain boundary sliding and rotational modes. This corresponds to a situation when the size of grains in the particle has reduced to nanometric. Similar deformation mechanisms operate at superplastic deformation of micron and submicron grained alloys at elevated temperatures where accommodation of grains takes place via grain boundary diffusion (Kaibyshev, 2002) and vacancies arising in the boundary may penetrate into grains. However, as noted in (Shtremel', 2007), a mechanism via which disclinations can generate vacancies is not described in (Gapontsev \& Koloskov, 2007), and estimates for the vacancy generation rate are not presented in (Gapontsev et al., 2000; Gapontsev et al., 2002; Gapontsev et al., 2003). Besides, the interaction of vacancy flux in a grain with edge dislocations, which can substantially reduce the vacancy concentration, is not considered, i.e. it is implied that nonograins, whose typical size in the powders processed by MA lies within 20-100 nm, do not contain dislocations. But experimental observations using high-resolution transmission electron microscopy have revealed that dislocation density in nanograined $\mathrm{Ni}(20-30 \mathrm{~nm})$ obtained by IPD (particularly, accumulative roll bonding) is very high, $\sim 10^{12} \mathrm{~cm}^{-2}$ (Wu \& Ma, 2006).

Thus, models (Gapontsev \& Koloskov, 2007; Gapontsev et al., 2000; Gapontsev et al., 2002; Gapontsev et al., 2003) can be considered as incomplete and relating to a distant stage of MA where nanorgains of a solid solution or intermetallic compound have already been formed via a certain physical mechanism which was not considered in these works.

An idea of solid solution formation during MA by the "shear-drift diffusion" (Foct, 2004) or "trans-phase dislocation shuffling" (Raabe et al., 2009; Quelennec et al., 2010) has been proposed, which the authors of these works base upon the certain outcomes of atomistic simulations (Bellon \& Averback, 1995). Since this viewpoint has acquired a certain use in literature, it is necessary to analyze it in detail. It is implied that during plastic deformation, which in crystalline solids is produced by dislocations gliding over glide planes, dislocations can cross the phase boundary. At large strains or strain rates the dislocation glide may occur over intersecting glide planes. According to the above concept, this results in "trans-phase dislocation shuffling" of groups of atoms at the boundary. In other words, after several dislocations gliding over different planes have crossed the phase boundary between dissimilar metals, say the A/B boundary, a group of atoms A originally located in phase A near the interface appears inside phase B (see Fig.9 in (Raabe et al., 2009)).

Although this qualitative concept seems clear and simple from the viewpoint of the classical dislocation theory and continuum mechanics, it contradicts the existing theories of plastic deformation of bulk polycrystalline materials, both coarse-grained (with micron-sized grains) and nanograined. During plastic deformation of polycrystals with grain size of the order of 1-100 $\mu \mathrm{m}$, the dislocations that glide from an intragrain source (a Frank-Read source) towards a grain boundary under the action of shear stress cannot "burst" through the boundary (Meyers \& Chawla, 2009): they accumulate near the latter forming the socalled pile-ups where the number of piled dislocations is $\sim 10^{2}-10^{3}$. The arising elastic stress activates a Frank-Read source in the adjacent grain, which results in macroscopic deformation revealing itself in a step-like displacement of the grain boundary. This theory results in the known Hall-Petch equation which shows a good agreement with numerous experimental data. Gliding dislocations can really cross a phase boundary, but only in the case of a coherent (or at least semi-coherent) interface between a matrix and a small-sized 
inclusion of a strengthening phase, which has formed during ageing of precipitationhardening alloys. This brings about matched co-deformation of the matrix and precipitate, or shearing of a particle, which is accompanied with interface steps formation (Argon, 2008). In (Raabe et al., 2009), it is speculated that dislocations can cross a phase boundary in a nanograined material under a high shear stress. It is argued that a $<111>$ texture formed at co-deformation of two fcc phases ( $\mathrm{Cu}$ and $\mathrm{Ag}$ ) during drawing of $\mathrm{Cu}-5$ at.\% Ag-3 at.\% Nb wires with a maximal true strain of 10.5 brings about the matching of highly stressed slip systems in both phases, and this consideration is used as an argument for the dislocation shuffling concept. However, the existence of same orientation of grains is a necessary but insufficient condition. A boundary between dissimilar metals formed by cold welding during MA is typically a non-coherent high-angle one and, in a special case, it may convert into a low-angle boundary due to grain-boundary sliding and grain rotation during IPD. But the authors of the cited work did not propose a physical mechanism via which a noncoherent boundary could convert into a coherent or at least a semi-coherent one.

In alloys with submicrocrystalline/nanograined structure, where the Hall-Petch law is not valid, deformation proceeds via different mechanisms. In nanosized grains the traditional Frank-Read sources of dislocations cannot operate because of lack of space. Then the leading dislocation in a pile-up formed near a grain boundary will interact with the interface, which results in absorption of dislocation by the latter, i.e. conversion into a grain-boundary dislocation accompanied with its core spreading (delocalization) (Segal et al., 2010). This results in grain-boundary sliding and may bring about rotational modes of deformation. In this case, triple grain junctions (disclinations) and non-equilibrium grain boundaries act as sources of dislocations for an adjacent grain (Segal et al., 2010; Gutkin et al., 2001; Bobylev et al., 2009; Gutkin et al., 2005), which results in deformation of the material as a whole. The dislocations (actually, dislocations semiloops) emitted by the grain boundary are blown like bubbles into the next grain by the shear strain; a similar phenomenon was observed at lowangle grain/subgrain boundaries during hot deformation of traditional (with micron-sized grains) metals and alloys (see Figs.3.12 and 3.13 in (Levitin, 2006)).

This concept is supported by atomistic modeling (Wang et al., 2008) for a Cu-Nb system: "a single mixed dislocation, from either $\mathrm{Cu}$ or $\mathrm{Nb}$, cannot cross the interface even at resolved shear stresses in excess of $1.0 \mathrm{GPa}$. Thus, a non-coherent grain/phase boundary is typically an impermeable obstacle for dislocation glide in both micro and nanograined crystalline materials. Hence, in (Raabe et al., 2009), where work (Wang et al., 2008) was cited, the results of molecular-dynamics simulations performed in the latter were misinterpreted.

So, the qualitative concept of "shear-drift diffusion" or "dislocation shuffling" does not correspond to a real situation in MA and thus appears to be physically meaningless.

From the above brief analysis it is seen that, despite a number of attempts, a physically grounded model for the formation of (supersaturated) solid solutions in metallic systems during IPD and, in particular, MA has not been developed so far. This stage of MA is of primary scientific and technological importance since the goal of MA is the production of a far-from-equilibrium product possessing advanced properties.

\section{Formulation of the model}

\subsection{Physical background and basic assumptions}

As a physical situation, we consider an individual lamellar particle formed at an initial stage of MA due to fracturing of cold welding of initial metal particles, and separate a unit 
structural element, viz. diffusion couple "metal B (phase 2)-metal A (phase 1)" where diffusion mass transfer occurs during MA. In binary metal systems, diffusion in normal conditions proceeds mainly via a substitutional (vacancy) mechanism. Since the directions of incidental ball-powder-ball and ball-powder-wall collisions in a milling device are chaotic, we neglect a change of the diffusion-couple geometry, and reduce the role of plastic deformation only to the formation of defects in the crystal lattice of both phases.

It has been demonstrated experimentally that in many substitutional systems under IPD the enhanced solid-state diffusion mass transfer in a wide temperature range is dominated by volume rather than grain boundary diffusion (Larikov et al., 1975; Gertsriken et al., 1983; Arsenyuk et al., 2001a; Arsenyuk et al., 2001b; Gertsriken et al., 1994; Gertsriken et al., 2001). Since we consider early stages of MA, when the initial concentration gradient at the phase boundary $2 / 1$ is very high, it seems reasonable to assume that phase transformation (e.g., formation of an intermetallic compound) at this interface does not occur, i.e. only diffusion of atoms A and B across the initial boundary can take place. This physical assumption is based on the results of works (Khusid \& Khina, 1991; Desre \& Yavari, 1990; Desre, 1991; Gusak et al., 2001) where it has been demonstrated using both kinetic (Khusid \& Khina, 1991; Gusak et al., 2001) and thermodynamic (Desre \& Yavari, 1990; Desre, 1991) considerations that in the field of a sharp concentration gradient in a binary metallic system nucleation of an equilibrium phase, e.g., intermetallic compound, is suppressed and can occur only after the gradient decreases in the course of diffusion to a certain critical level.

Volume diffusion in substitutional alloys (at close diameters of A and B atoms) can be strongly influenced by the formation of non-equilibrium vacancies and also by generation of interstitial atoms whose diffusion rate is high. In a number of works on IPD, the phenomenon of enhanced diffusion is attributed to the interstitial mechanism (Larikov et al., 1975; Skakov, 2004): highly mobile interstitial atoms (say, of sort A), which in binary substitutional solid solutions normally diffuse via a vacancy mechanism, are formed at the A/B interface due to "pushing" of lattice atoms A into interstices of crystal lattice B by the shear stress. After that, they rapidly diffuse in metal B in the field of an external force, e.g., a pressure jump generated by an incidental collision during MA or by explosion at shockwave processing of metals. This mechanism is similar to the ballistic effects observed in reactor materials under radiation (Bullough et al., 1975; Murphy, 1987; Mansur, 1979) or at ion-beam processing of metals. However, molecular-dynamics simulation has revealed that for this mechanism to operate, local pressure at the phase boundary must be $\sim 100 \mathrm{GPa}$ (Gusak \& Bushin, 1996), which is typical of explosion processing, whereas the mechanistic modeling of MA in ball mills has demonstrated that the maximal pressure during collisions is $~ 1 \mathrm{GPa}$ (Maurice \& Courtney, 1990; Lovshenko \& Khina, 2005), i.e. substantially lower. That is why this mechanism is not relevant to "traditional" MA/IPD processes and hence is not considered here. Besides, within the above concept it is not specified what happens with the crystal lattice of metal B near the interface when foreign atoms A are "pushed" into interstitial positions of the former in a mass quantity.

In traditional polycrystalline materials with micron-size grains, dislocation glide is the dominating mechanism of plastic deformation (Nabarro et al., 1964; Novikov, 1983; Hirth \& Lothe, 1982). As noted earlier, nanocrystalline materials with a grain size of 20-30 nm produced by IPD feature a high density of lattice dislocations (Wu \& Ma, 2006). Moleculardynamics simulations performed for copper (Vo et al., 2008) have unambiguously shown that even at very high strain rates (up to $10^{10} \mathrm{~s}^{-1}$ ), which correspond to shock-wave processing of metals, dislocations account for $90 \%$ of the strain at the grain size of $20 \mathrm{~nm}$, 
and the role of grain boundary sliding, which corresponds to the remaining $10 \%$, decreases with strain. This outcome of modeling is supported by experimental observations (Gurao \& Suwas, 2009): the major contribution to plastic strain at IPD (rolling to 90\% reduction in thickness) of nanocrystalline $\mathrm{Ni}$ with a grain size of about $20 \mathrm{~nm}$ occurs through normal dislocation slip. It is known that during deformation of metals via the dislocation mechanism, excess point defects (vacancies and self-interstitials) are produced due to interaction of gliding dislocations (Nabarro et al., 1964; Novikov, 1983). Hence, it this model we consider namely this route of point defect generation.

\subsection{Derivation of the model equations}

Let us define the concentration of species in ratio to the density of lattice sites $\mathrm{N}_{0}$ (Voroshnin \& Khusid, 1979): $c_{k}=N_{k} / N_{0}$, where $N_{k}$ is a number of $k$-th species per unit volume. Here the species in phases 1 and 2 are lattice atoms $A$ and $B$, vacancies $v$ and interstitial atoms $A$ and $B$, which are denoted as $A_{i}$ and $B_{i}$. Since $N_{0}=N_{B}+N_{A}+N_{v}$, then $c_{B}+c_{A}+c_{v}=1$, and thus the overall sum including the concentration of interstitials will exceed unity.

The diffusion mass transfer equation looks as (Adda \& Philibert, 1966; Gurov et al., 1981):

$$
\partial c_{k} / \partial t=-\operatorname{div} J_{k}+F_{k}, \mathrm{k} \equiv \mathrm{A}, \mathrm{B}, \mathrm{v}, \mathrm{A}_{\mathrm{i}}, \mathrm{B}_{\mathrm{i}}
$$

where $F_{k}$ is the sink/source term for $k$-the species and $J_{k}$ is the diffusion flux. Neglecting the gradient of the lattice site density $\partial \mathrm{N}_{0} / \partial \mathrm{x}$, let us write the expression for diffusion fluxes of lattice atoms $\mathrm{A}$ and $\mathrm{B}$ and vacancies $\mathrm{v}$ taking into account the interconnection of fluxes via the cross-term, or off-diagonal interdiffusion coefficients following the classical theory of diffusion in solids (Voroshnin \& Khusid, 1979; Adda \& Philibert, 1966; Gurov et al., 1981):

$$
J_{k}=-\sum_{n} D_{k n} \operatorname{grad}_{n}, \quad \sum_{k} J_{k}=0, \mathrm{k}, \mathrm{n} \equiv \mathrm{A}, \mathrm{B}, \mathrm{v},
$$

where $D_{\mathrm{kn}}$ are elements of the matrix of interdiffusion coefficients.

For diffusion fluxes of atoms and vacancies $v$, interdiffusion coefficients $D_{k n}$ that appear in Eq. (2) can be determined using the theory of diffusion in solid solutions with non-uniform vacancy distribution (Gurov et al., 1981). We take into account that self-diffusion coefficient $\mathrm{D}^{*}$ in quasi-equilibrium conditions, i.e. at an anneal without external influences, is estimated as $D^{*}=f_{c} D_{v} c_{v}{ }^{0}$, where $c_{v}{ }^{0}$ is the equilibrium vacancy concentration at a given temperature, $D_{v}$ is the vacancy diffusion coefficient, $D_{v}>>D^{*}$, and $f_{c} \approx 1$ is the correlation factor. Then in the case when non-equilibrium vacancies are present in a solid solution, i.e. $c_{v}>>c_{v}{ }^{0}$, the diffusion coefficient of atoms will increase proportionally to term $c_{v} / c_{v}{ }^{0}$. Hence we have

$$
\begin{aligned}
& \mathrm{D}_{\mathrm{BB}}=\mathrm{D}_{\mathrm{B}}{ }^{*}\left(\mathrm{~g}_{\mathrm{BB}}-\mathrm{g}_{\mathrm{AB}}\right) \mathrm{c}_{\mathrm{v}} / \mathrm{c}_{\mathrm{v}}{ }^{0}, \mathrm{D}_{\mathrm{AA}}=\mathrm{D}_{\mathrm{A}} *\left(\mathrm{~g}_{\mathrm{AA}}-\mathrm{g}_{\mathrm{BA}}\right) \mathrm{c}_{\mathrm{v}} / \mathrm{c}_{\mathrm{v}}{ }^{0}, \\
& \mathrm{D}_{\mathrm{Bv}}=-\mathrm{D}_{\mathrm{B}}{ }^{*} \mathrm{c}_{\mathrm{B}} / \mathrm{c}_{\mathrm{v}}{ }^{0}, \mathrm{D}_{\mathrm{vB}}=\mathrm{D}_{\mathrm{AA}}-\mathrm{D}_{\mathrm{BB}}, \\
& \mathrm{D}_{\mathrm{vv}}=\mathrm{D}_{\mathrm{v}}+\mathrm{D}_{\mathrm{AA}}, \mathrm{D}_{\mathrm{v}}=\left[\mathrm{c}_{\mathrm{B}} \mathrm{D}_{\mathrm{B}}{ }^{*}+\mathrm{c}_{\mathrm{A}} \mathrm{D}_{\mathrm{A}}{ }^{*}\right] / \mathrm{c}_{\mathrm{v}}{ }^{0} \\
& \mathrm{~g}_{\mathrm{kk}}=1+\partial\left(\ln \gamma_{\mathrm{k}}\right) / \partial\left(\ln \mathrm{c}_{\mathrm{k}}\right), \mathrm{g}_{\mathrm{kj}}=\left(\mathrm{c}_{\mathrm{k}} / \mathrm{c}_{\mathrm{j}}\right) \partial\left(\ln \gamma_{\mathrm{k}}\right) / \partial\left(\ln \mathrm{c}_{\mathrm{j}}\right), \mathrm{k}, \mathrm{j} \equiv \mathrm{A}, \mathrm{B}, \mathrm{k} \neq \mathrm{j},
\end{aligned}
$$

where $D_{B}{ }^{*} и D_{A}{ }^{*}$ are the self-diffusion coefficients of atoms $A$ and $B$ in the given phase $(1$ or $2), g$ is the thermodynamic factor and $\gamma$ is the activity coefficient. As a common first approximation, the solid solutions are considered to be ideal and then $\mathrm{g}_{\mathrm{kk}}=1, \mathrm{~g}_{\mathrm{kj}}=0$. 
As seen from Eqs. (3), increasing the vacancy concentration above $c_{v}{ }^{0}$ substantially raises the diffusion coefficient. This corresponds to an increase in the pre-exponential factor $\mathrm{D}_{0}$ in the Arrhenius formula $D^{*}=D_{0} \exp [-E /(R T)]$ at an almost unchanged activation energy E. This is connected with the vacancy diffusion mechanism in substitutional solid solutions where $\mathrm{E}$ is the energy barrier height for an atomic jump on the adjacent vacant position while $D_{0}$ is related to the number of available vacant sites, the latter being proportional to $c_{v}$.

Excess point defects are generated during deformation, i.e. at short-time collisions during MA in a ball mill. Relaxation of point defects towards equilibrium concentration during intervals between collisions occurs by two basic mechanisms: (i) interaction with edge components of dislocation loops, which act as volume-distributed sinks; in this case intersitials $A_{i}$ and $B_{i}$ become lattice atoms of the corresponding sort, and (ii) vacancyinterstitial annihilation, as a result of which an interstitial atom becomes a lattice one. To describe the rates of these processes we use certain results of the theory of defects in irradiated alloys (Bullough et al., 1975; Murphy, 1987; Mansur, 1979). The equilibrium concentration of self-interstitials in crystalline metals is typically assumed to be negligibly small. Then the rate of vacancy-interstitial annihilation is proportional to the deviation of the vacancy concentration from the equilibrium value times the concentration of selfinterstitials. The rate of point defect adsorption by edge dislocations is proportional to the density of the latter, the diffusion coefficient of point defects and their concentration.

Then the equations for concentrations of diffusing species, viz. atoms $B$, vacancies and interstitials $B_{i}$ and $A_{i}$ in each phase are formulated as following:

$$
\begin{gathered}
\frac{\partial c_{B}}{\partial t}=\frac{\partial}{\partial x}\left(D_{B B} \frac{\partial c_{B}}{\partial x}+D_{B v} \frac{\partial c_{v}}{\partial x}\right)-P_{i} c_{B i}+\zeta_{B i} D_{B i} c_{B i} \rho_{e}+K_{i v}\left(c_{v}-c_{v}^{0}\right) c_{B i} \\
\frac{\partial c_{v}}{\partial t}=\frac{\partial}{\partial x}\left(D_{v B} \frac{\partial c_{B}}{\partial x}+D_{v v} \frac{\partial c_{v}}{\partial x}\right)+P_{v}-\zeta_{v} D_{v}\left(c_{v}-c_{v}^{0}\right) \rho_{e}-K_{i v}\left(c_{v}-c_{v}^{0}\right)\left(c_{B i}+c_{A i}\right) \\
\frac{\partial c_{B i}}{\partial t}=\frac{\partial}{\partial x}\left(D_{B i} \frac{\partial c_{B i}}{\partial x}\right)+P_{i} c_{B}-\zeta_{B i} D_{B i} c_{B i} \rho_{e}-K_{i v}\left(c_{v}-c_{v}^{0}\right) c_{B i} \\
\frac{\partial c_{A i}}{\partial t}=\frac{\partial}{\partial x}\left(D_{A i} \frac{\partial c_{A i}}{\partial x}\right)+P_{i} c_{A}-\zeta_{A i} D_{A i} c_{A i} \rho_{e}-K_{i v}\left(c_{v}-c_{v}^{0}\right) c_{A i} \\
c_{B}+c_{A}+c_{v}=1 .
\end{gathered}
$$

Here $D_{B i}$ and $D_{A i}$ are the diffusion coefficients of interstitial atoms, $P_{i}$ and $P_{v}$ are the generation rates of interstitials and vacancies per unit volume of an alloy, $\rho_{e}$ is the density of edge dislocations, $\zeta_{\mathrm{Ai}}, \zeta_{\mathrm{Bi}}$ and $\zeta_{\mathrm{v}}$ are dimensionless coefficients describing the efficiency of edge dislocations as sinks point defects, $\zeta_{\mathrm{k}} \approx 1, \mathrm{k} \equiv \mathrm{A}_{\mathrm{i}}, \mathrm{B}_{\mathrm{i}, \mathrm{V}}$ (Bullough et al., 1975; Murphy, 1987; Mansur, 1979), and $K_{\mathrm{iv}}$ is the vacancy-interstitial recombination rate per unit volume.

Unlike radiation damage of reactor materials, where Frenkel pairs and collision cascades are formed due to knocking lattice atoms out of their regular positions by high-energy particles, the basic mechanism of non-equilibrium point-defect generation in metals under plastic deformation is jog dragging by gliding screw dislocations. The jogs are formed on gliding edge and screw dislocations during intersection with the forest dislocations, i.e. those not 
involved in the active glide system. Jogs on edge dislocations move together with the dislocation while those on screws act as obstacles for the dislocation glide. Under shear stress, a screw dislocation bends and drags the jogs, which produce excess vacancies or interstitial atoms depending on the jog sign (Nabarro et al., 1964; Novikov, 1983). The defect production rates $P_{\mathrm{v}}$ and $P_{\mathrm{i}}$ are described using the Hirsch-Mott theory (Nabarro et al., 1964):

$$
P_{v}=(\dot{\varepsilon} b / 2)\left(f_{v} \xi \rho / 2\right)^{1 / 2}, \quad P_{i}=(\dot{\varepsilon} b / 2)\left(f_{i} \xi \rho / 2\right)^{1 / 2},
$$

Here $\rho$ is the total dislocation density, $\rho_{\mathrm{s}} \approx \rho_{\mathrm{e}}=\rho / 2$ where $\rho_{\mathrm{s}}$ is the density of screws (Novikov, 1983), $\xi$ is the fraction of forest dislocations (usually $\xi \approx 0.5$ ), $b$ is the Burger vector length, $\dot{\varepsilon}$ is the strain rate, $\mathrm{f}_{\mathrm{v}}$ and $\mathrm{f}_{\mathrm{i}}$ are the fractions of vacancy and interstitial producing jogs, $f_{v}+f_{i}=1$, and typically $f_{v}>f_{i}$ (Nabarro et al., 1964; Novikov, 1983).

The recombination-rate coefficient $K_{\mathrm{iv}}$ in a binary solid solution is determined as

$$
\mathrm{K}_{\mathrm{iv}}=\left(4 \pi \mathrm{r}_{0} / \omega\right)\left(\mathrm{D}_{\mathrm{i}}+\mathrm{D}_{\mathrm{v}}\right) \text {, }
$$

where $r_{0}$ is the capture radius, $\omega=\mathrm{a}_{0}{ }^{3}$ is the average volume of a crystal cell, $\mathrm{a}_{0}$ is the lattice period. The capture radius is usually determined as $r_{0}=b / 2$ (Bullough et al., 1975; Murphy, 1987; Mansur, 1979), where the b is the Burgers vector. In the theory of radiation-induced diffusion it is considered that the diffusion coefficient of self-interstitials is by several orders of magnitude higher than that of vacancies (Murphy, 1987; Mansur, 1979). For modeling we assume that $\mathrm{D}_{\mathrm{Ai}}, \mathrm{D}_{\mathrm{Bi}} \sim 10^{3} \mathrm{D}_{\mathrm{v}}$, where $\mathrm{D}_{\mathrm{v}}$ is defined by formulas (3).

\subsection{Initial and boundary conditions}

To complete the problem, diffusion mass transfer equations (4)-(7) should be supplemented with relevant initial and boundary conditions. For definiteness, let phase 2 (initially pure metal $\mathrm{B}$ ) be on the left (with respect to the direction of the coordinate axis $\mathrm{x}$ ) and phase 1 (initially pure metal A) on the right. The thickness of the diffusion couple L consists of two half-thicknesses of the corresponding metal layers. Then the initial conditions look as

$$
\mathrm{c}_{\mathrm{Bi}}(\mathrm{x})=\mathrm{c}_{\mathrm{Ai}}(\mathrm{x})=0, \mathrm{c}_{v}(\mathrm{x})=\mathrm{c}_{v}^{0} \text { at } 0<\mathrm{x}<\mathrm{L}, \mathrm{c}_{\mathrm{B}}(\mathrm{x})=1 \text { at } 0<\mathrm{x}<\mathrm{g}, \mathrm{c}_{\mathrm{B}}(\mathrm{x})=0 \text { at } \mathrm{g}<\mathrm{x}<\mathrm{L}
$$

where $\mathrm{g}=\mathrm{L} / 2$ is the coordinate of the $2 / 1$ interface.

The Neumann-type boundary conditions to Eqs. (4)-(7) at $x=0$ and $x=L$ are

$$
\mathrm{J}_{\mathrm{k}}(\mathrm{x}=0, \mathrm{~L})=0, \mathrm{k} \equiv \mathrm{B}, \mathrm{v}, \mathrm{B}_{\mathrm{i}}, \mathrm{A}_{\mathrm{i}} .
$$

For vacancy diffusion, an additional boundary condition is posed at the $2 / 1$ interface:

$$
\mathrm{c}_{v}(\mathrm{x}=\mathrm{g})=\mathrm{c}_{v}^{0} .
$$

Condition (13) is determined by the fact that the interface between starting pure metals A and B is incoherent and consists of grain-boundary dislocations (Kosevich et al., 1980) and hence can act as a localized sink for non-equilibrium point defects.

Since problem (3)-(13) describing diffusion in substitutional alloys in the conditions of IPD is substantially nonlinear, it can be solved only numerically. For this purpose, a computer procedure is developed employing a fully implicit finite-difference scheme, which is derived using the versatile integration-interpolation method (Kalitkin, 1978). 


\section{Parameter values for modeling}

We consider a deformation-relaxation cycle with parameters typical of MA in vibratory mill "SPEX 8000" with oscillation frequency $\omega=20 \mathrm{~Hz}$, then the cycle duration is $t_{c}=(2 \omega)^{-1}=$ 0.025 s. Deformation, when point defect are generated, occurs during collisions whose duration is $\mathrm{t}_{\mathrm{d}} \sim 10^{-4} \mathrm{~s}$, and a lower-level estimate for strain rate is $\dot{\varepsilon} \sim 10 \mathrm{~s}^{-1}$ (Maurice \& Courtney, 1990; Lovshenko \& Khina, 2005). Then the interval between collisions, when relaxation occurs $\left(P_{i}=P_{v}=0\right)$, is $t_{r}=t_{c}-t_{d}=0.0249 \mathrm{~s}$. The thickness of metal layers in lamellar particles is $0.5-0.05 \mu \mathrm{m}$; we assume $\mathrm{L}=0.1 \mu \mathrm{m}$. The dislocation density is $\rho \sim 10^{11}-10^{12} \mathrm{~cm}^{-2}$; we take $\rho=10^{11} \mathrm{~cm}^{-2}$. Since $f_{v}>f_{i}$ (Nabarro et al., 1964; Novikov, 1983), we suppose $f_{v} / f_{i}=2$.

The following model binary system is considered: $\mathrm{Al}$ (metal B, phase 2)-Cu (metal A, phase 1). At collisions during MA in a vibratory mill, a local temperature rise in particles is small: $10 \mathrm{~K}$ for $\mathrm{Al}$ and about $20 \mathrm{~K}$ for $\mathrm{Cu}$ (Maurice \& Courtney, 1990), and thus its influence on diffusion coefficients $\mathrm{D}_{\mathrm{B}}{ }^{*}, \mathrm{D}_{\mathrm{A}}{ }^{*}$ is negligible. We take a constant process temperature, $\mathrm{T}_{\mathrm{MA}}=$ $100^{\circ} \mathrm{C}=373 \mathrm{~K}$, which corresponds to an industrial milling device with a water-cooled shell. The equilibrium vacancy concentration in both phases is determined as

$$
\mathrm{c}_{v}^{0}=\exp \left[-\Delta \mathrm{H}_{v}^{f} /\left(\mathrm{k}_{\mathrm{B}} \mathrm{T}\right)\right],
$$

where $\Delta \mathrm{H}_{\mathrm{v}} \mathrm{f}$ is the vacancy formation enthalpy and $\mathrm{k}_{\mathrm{B}}$ is the Boltzmann constant.

The values of $E$ and $D_{0}$ for calculating self-diffusion coefficients $D_{B}{ }^{*}, D_{A}{ }^{*}$, the Burgers vector, vacancy formation enthalpy and the estimated parameter values at $\mathrm{T}_{\mathrm{MA}}$ are listed in Table 1 . It is seen that in equilibrium conditions parameters $\mathrm{D}^{*}$ and $\mathrm{c}_{\mathrm{v}}{ }^{0}$ in both phases are very small.

\begin{tabular}{|c|c|c|c|c|c|c|c|c|c|}
\hline \multirow{2}{*}{$\begin{array}{c}\text { species/ } \\
\text { phases }\end{array}$} & \multicolumn{3}{|c|}{ phase $2(\mathrm{Al})$} & \multicolumn{3}{|c|}{ phase $1(\mathrm{Cu})$} & \multirow{2}{*}{$\begin{array}{c}\Delta \mathrm{H}_{\mathrm{v}}^{\mathrm{f}}, \\
\mathrm{eV}\end{array}$} & \multirow{2}{*}{$\mathrm{c}_{\mathrm{V}}{ }^{0}\left(\mathrm{~T}_{\mathrm{MA}}\right)$} & \multirow{2}{*}{$\mathrm{b}, \mathrm{cm}$} \\
\hline & $\begin{array}{c}\mathrm{D}_{0}, \\
\mathrm{~cm}^{2} / \mathrm{s}\end{array}$ & $\begin{array}{c}\mathrm{E}, \\
\mathrm{kJ} / \mathrm{mol}\end{array}$ & $\begin{array}{c}\mathrm{D}^{*}\left(\mathrm{~T}_{\mathrm{MA}}\right) \\
\mathrm{cm}^{2} / \mathrm{s}\end{array}$ & $\begin{array}{c}\mathrm{D}_{0}, \\
\mathrm{~cm}^{2} / \mathrm{s}\end{array}$ & $\begin{array}{c}\mathrm{E}, \\
\mathrm{kJ} / \mathrm{mol}\end{array}$ & $\begin{array}{c}\mathrm{D}^{*}\left(\mathrm{~T}_{\mathrm{MA}}\right) \\
\mathrm{cm}^{2} / \mathrm{s}\end{array}$ & & & \\
\hline $\mathrm{Al}$ & 1.71 & 142.3 & $2.0 \cdot 10^{-20}$ & 0.3 & 196.8 & $8.6 \cdot 10^{-29}$ & 0.76 & $5.4 \cdot 10^{-11}$ & $2.86 \cdot 10^{-8}$ \\
\hline $\mathrm{Cu}$ & 0.647 & 135 & $7.8 \cdot 10^{-20}$ & 0.2 & 196.4 & $6.6 \cdot 10^{-29}$ & 1.17 & $1.6 \cdot 10^{-16}$ & $2.55 \cdot 10^{-8}$ \\
\hline
\end{tabular}

Table 1. Parameters $\mathrm{D}_{0}$ and $\mathrm{E}$ for self and impurity diffusion in $\mathrm{Al}$ and $\mathrm{Cu}$ (Brandes \& Brook, 1992), the vacancy formation enthalpy (Bokshtein, 1978), Burgers vector (Brandes \& Brook, 1992) and the parameters values calculated for $T_{M A}=373 \mathrm{~K}$

\section{Numerical results and discussion}

The results of computer simulations with the above described parameters are presented in Figs. 1-3 for different situations. In the first case, boundary condition (13) was not considered, i.e. phase boundary $2 / 1$ was assumed to be permeable for vacancy diffusion and did not work as a sink. This refers to a hypothetical situation of a coherent phase boundary, which for some reason retains during deformation. Here, relaxation of nonequilibrium point defects occurs via vacancy-interstitial annihilation and interaction with volume-distributed sinks (edge dislocations). In this case, atoms $\mathrm{B}$ (Al) diffuse into phase 1 (Cu-base solid solution), i.e. the concentration profile is asymmetrical (see Fig. 1 (a)). 

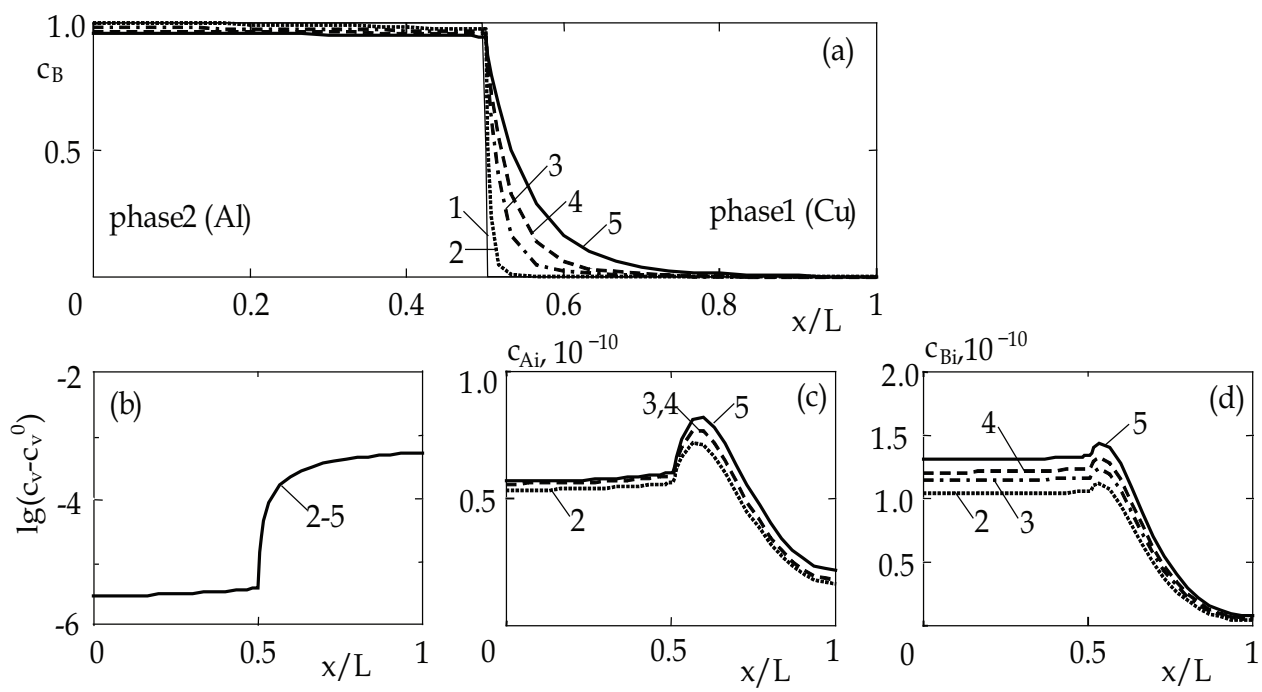

Fig. 1. Calculated concentration profiles of atoms $B(a)$, vacancies (b) and interstitial atoms $A_{i}(c)$ and $B_{i}(d)$ when the 2/1 interface is not a sink for vacancies: $1, t=0 ; 2, t=250 \mathrm{~s}(10000$ cycles); $3, \mathrm{t}=1250 \mathrm{~s}$ ( 50000 cycles); $4, \mathrm{t}=2000 \mathrm{~s}$ ( 80000 cycles); $5, \mathrm{t}=4000 \mathrm{~s}$ (160000 cycles)

As a result of interplay between vacancy generation, diffusion and relaxation, which occur at different rates in phases 1 and 2, the concentration of non-equilibrium vacancies appears to be very high (Fig. 1 (b)), and in phase 1 it is substantially larger than in phase $2, \mathrm{c}_{\mathrm{v}}{ }^{(1)}>$ $\mathrm{C}_{\mathrm{v}}{ }^{(2)}$, where superscripts denote the phase numbers. The steady-state vacancy profile with a steep gradient near the interface $x=g$ (i.e. $x / L=0.5$ ) is established after a short time, about 200 s. As seen from Eq. (4), at a large value of term $\left|D_{B v} \partial c_{v} / \partial x\right|$ atoms $B$ will diffuse in the direction opposed to that of the diffusion flux of vacancies, which brings about noticeable diffusion alloying of copper with aluminum (metal $\mathrm{B}$ ) near the interface at a relatively short time, $4000 \mathrm{~s}$. The concentration of interstitials $A_{i}$ and $B_{i}$ is several orders of magnitude lower than that of vacancies (Fig 1, (c and d)), which is due to high annihilation rates in phases 1 and 2 and a large vacancy concentration. Since away from the $2 / 1$ interface $c_{v}(1)>c_{v}(2)$, the concentration of interstitials $A_{i}$ and $B_{i}$ in phase 1 is lower than in phase 2 . The peaks in the concentration profiles of interstitials in phase 1 near the 2/1 interface (see Fig 1, (c and d)) are attributed to the existence of a steady-state profile of vacancies. Thus, acceleration of diffusion in the conditions of MA is connected not only with a substantial increase of the partial diffusion coefficients, $\mathrm{D}_{\mathrm{BB}}$ and $\mathrm{D}_{\mathrm{AA}}$, due to a high vacancy concentration (see Eqs. (3)) but also with interaction of diffusion fluxes of atoms and vacancies via off-diagonal terms $\mathrm{D}_{\mathrm{Bv}}, \mathrm{D}_{\mathrm{vB}}$. Such a cross-term effect is sometimes referred to as the "inverse Kirkendall effect". Results of simulations for a more realistic case, when the $2 / 1$ interface acts as localized sink for excess vacancies, i.e. boundary condition (13) is accounted for, are shown in Fig. 2.

Unlike the previous case, diffusion of atoms $\mathrm{A}(\mathrm{Cu})$ from phase 1 into phase 2 (Al-base solid solution) occurs (see Fig. 2 (a)). As in the previous situation, very high concentration of vacancies is observed inside both of the phases, and $c_{V}(1)>c_{V}(2)$. Since the equilibrium vacancy concentration is sustained at the interface, steep vacancy concentration gradients arise in phases 1 and 2 near the boundary, so the vacancy flux in each phase is directed to 
the interface and $\left|\partial c_{V}(1) / \partial x\right|_{x=g+0}>>\left|\partial c_{v}(2) / \partial x\right|_{x=g-0}$ (Fig. $\left.2(b)\right)$. The steady-state profile of vacancies is established after a longer time, about $1000 \mathrm{~s}$. As seen from Eqs. (4),(5), a countercurrent flux of vacancies accelerates the diffusion of lattice atoms while a co-current flux retards it. In the given situation, all of the above brings about alloying of phase 2 with atoms A $(\mathrm{Cu})$ within a relatively short time, $\mathrm{t}=4000 \mathrm{~s}$. A small peak of atoms $\mathrm{A}$ is seen at the interface at a large time (curve 5 in Fig. 2 (a)). Thus, interaction of vacancy fluxes, which arise due to vacancy generation under periodic IPD, with the phase boundary can have a selective influence on diffusion of different atoms (A and B) during MA. The concentration of interstitials $A_{i}$ and $B_{i}$ inside both of the phases are small as compared with vacancies (see Fig. 2 (c and d)). This is due to fast recombination of the former with excess vacancies whose concentration in phase 1 away from the interface is much higher than in phase 2.
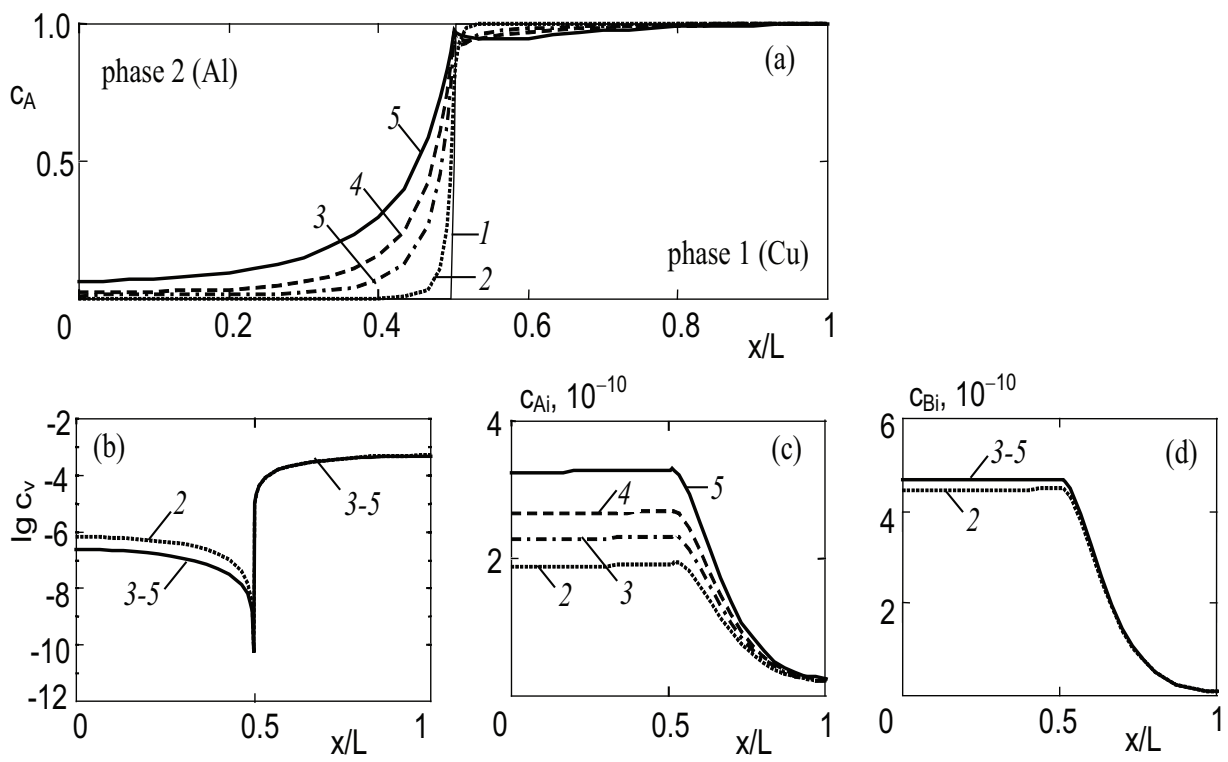

Fig. 2. Calculated concentration profiles of atoms A (a), vacancies (b) and interstitial atoms $A_{i}(c)$ and $B_{i}(d)$ when the $2 / 1$ interface acts as a localized sink for vacancies: $1, t=0 ; 2, t=250 \mathrm{~s}$ ( 10000 cycles); $3, t=1250$ s (50000 cycles); $4, t=2000$ s ( 80000 cycles); $5, t=4000$ s (160000 cycles)

Therefore, along with the accumulation of excess vacancies, increase in the diffusion coefficients and cross-term linking between the vacancy and atomic fluxes, important is the interaction of fluxes of non-equilibrium vacancies with the phase boundary. This factor has not previously received due attention in literature.

It should be noted that in the above situation the diffusion coefficients of atoms in phases 1 and 2 attain high values due to a high vacancy concentration while at the interface, where $\mathrm{C}_{\mathrm{V}}=\mathrm{C}_{\mathrm{V}}{ }^{0}, \mathrm{D}_{\mathrm{AA}}$ and $\mathrm{D}_{\mathrm{BB}}$ fall down to equilibrium, i.e. very low values. Thus, the interface acts as a diffusion barrier. But diffusion over grain boundaries proceeds substantially faster than in the volume at the same temperature. So, in the third case we consider that at $x=g$ the values of $\mathrm{D}_{\mathrm{BB}}$ and $\mathrm{D}_{\mathrm{AA}}$ correspond to the grain-boundary diffusion coefficients for corresponding pure metals. Using the data presented in (Mishin, 2001) for metals with fcc lattice (both $\mathrm{Cu}$ 
and $\mathrm{Al}$ ), we obtain the following estimates at $\mathrm{T}_{\mathrm{MA}}=373 \mathrm{~K}$ : for $\mathrm{Cu}($ metal $\mathrm{A}) \mathrm{D}_{\mathrm{AA}}(\mathrm{x}=\mathrm{g}) \sim 10^{-16}$ $10^{-17} \mathrm{~cm}^{2} / \mathrm{s}$, for $\mathrm{Al}$ (metal B) $\mathrm{D}_{\mathrm{BB}}(\mathrm{x}=\mathrm{g}) \sim 10^{-12} \mathrm{~cm}^{2} / \mathrm{s}$.

The results of simulation for this situation are presented in Fig. 3.
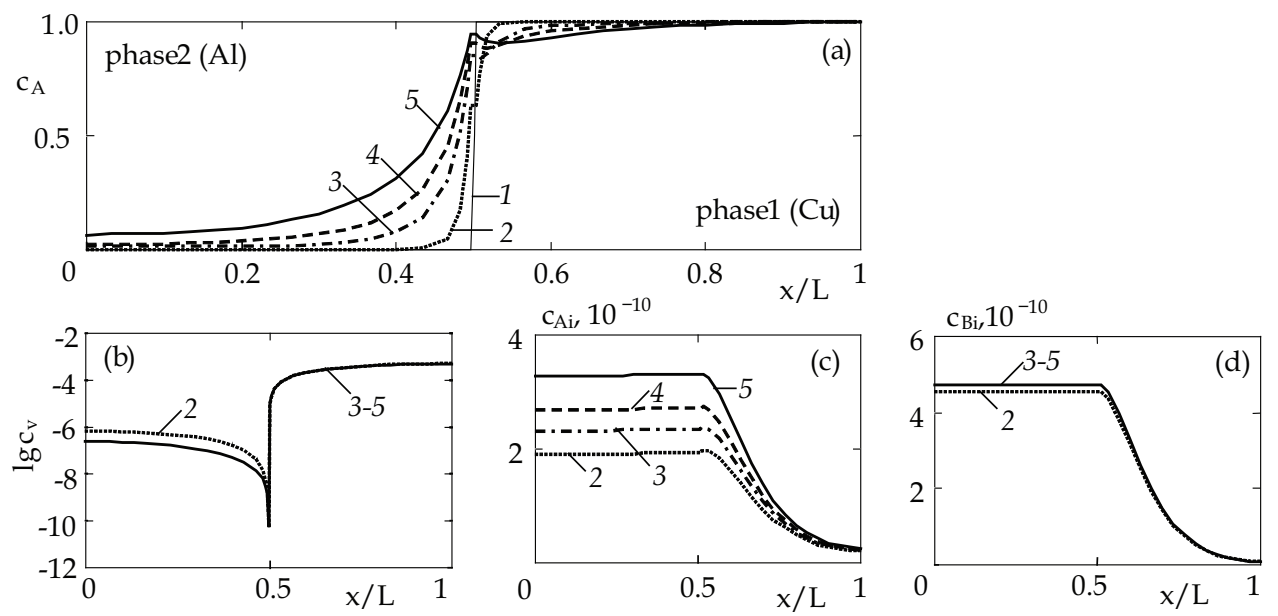

Fig. 3. Same is Fig. 2 but the values of diffusion coefficients of atoms A and B at the 2/1 interface correspond to the grain boundary diffusion

Since the barrier for atomic diffusion at the phase boundary is lower, the degree of alloying of phase $2(\mathrm{Al})$ with atoms $\mathrm{B}(\mathrm{Cu})$, i.e. total mass of the latter in the solid solution, has increased in comparison with the previous case. The peak of atoms A at the interface becomes more pronounced (Fig. 3 (a)); the concentration profiles of point defects (Fig. 3 (bd)) change insignificantly. Thus, interaction of diffusion fluxes of both vacancies and atoms with the interface is important in the enhancement of diffusion during MA.

The observed formation of solid solution within a short time of periodic IPD due to enhanced diffusion, and the revealed features of the process qualitatively agree with numerous experimental data on MA. In particular, asymmetric concentration profiles were observed in miscible (Fe-Ni, Fe-Co, Fe-Mn) and immiscible (Fe-Cu) systems as results of MA (Cherdyntsev \& Kaloshkin, 2010). The calculated vacancy concentration semi-quantitatively agrees with experimental data for copper after ECAP and ARB (Ungar et al., 2007): at the dislocation density of $4 \cdot 10^{11} \mathrm{~cm}^{-2}$ the value of $c_{\mathrm{v}}$ reached $5 \cdot 10^{-6}$ inside grains and up to $10^{-3} \mathrm{in}$ grain boundaries.

It should be noted that in this work we have used lower-level estimates for strain rate, which, according to the outcomes of mechanistic models, in the conditions of MA in a highspeed vibratory mill can reach $10^{4} \mathrm{~s}^{-1}$ (Maurice \& Courtney, 1990; Lovshenko \& Khina, 2005). It should be noted that at dynamic deformation regimes, i.e. high strain rates $(\dot{\varepsilon}>10$ $\mathrm{s}^{-1}$ ), the point defect production rates may be substantially higher (Popov et al., 1990) than predicted by the Hirsch-Mott theory (Eq. (9)). Besides, according to the theory of nonequilibrium grain boundaries, i.e. those in metals under the conditions of IPD (Segal et al, 2010), the grain-boundary diffusion coefficients will be orders of magnitude higher that the values used in this work. With all of these factors taken into account, diffusion mass transfer under the action of periodic IPD will proceed still faster. 


\section{Conclusion}

Thus, a consistent model of non-equilibrium enhanced solid-state diffusion in binary metallic systems during mechanical alloying has been developed, which accounts for the generation of non-equilibrium point defects due to jog dragging by gliding screw dislocations during plastic deformation at incidental collisions in a milling device and defect relaxation during time intervals between collisions. Numerical simulations using realistic values of the diffusion parameters for a model system $(\mathrm{Cu}-\mathrm{Al})$ at $100{ }^{\circ} \mathrm{C}$ have demonstrated a possibility of considerable alloying within a short time of MA (Khina et al., 2005; Khina \& Formanek, 2006). The acceleration of diffusion mass transfer is connected with the interplay and competition of several factors: (i) accumulation of non-equilibrium vacancies due to their fast generation during plastic deformation and slow relaxation in the intervals between collisions, (ii) increase of partial diffusion coefficients due to excess vacancies, (iii) cross-link interaction of diffusion fluxes via off-diagonal diffusion coefficients, and (iii) interaction of the diffusion fluxes of both vacancies and atoms with the phase boundary. The role of interstitial atoms is minor in comparison with non-equilibrium vacancies.

Fast diffusion that results in the formation of a zone of supersaturated solid solution around the interface, along with accumulation of excess vacancies inevitably increases the free energy of the alloy and causes a distortion of the crystal lattice. This may ultimately bring about a non-equilibrium phase transition such as solid-state amorphization: for example, in pure copper the latter can occur at $\mathrm{c}_{\mathrm{v}}=0.077$ (Fecht, 1992).

One of the prospective directions of further research is combining the developed model with a theory for dislocation evolution during IPD to obtain a comprehensive picture of structure formation. Also, it seems interesting to unite this approach with the theory of solid-state amorphization (Gusak at al., 2001) to get an opportunity to predict metastable phase transitions during MA.

\section{References}

Benjamin, J.S. (1992). Fundamentals of mechanical alloying. Materials Science Forum, Vol. 8890, pp. 1-18, ISSN 1662-9752

Koch, C.C. (1992). The synthesis of non-equilibrium structures by ball-milling. Materials Science Forum, Vol. 88-90, pp. 243-262, ISSN 1662-9752

Koch, C.C. (1998). Intermetallic matrix composites prepared by mechanical alloying-a review. Materials Science and Engineering A, Vol. 244, No. 1, pp. 39-48, ISSN 09215093

Ma, E. \& Atzmon, M. (1995). Phase transformations induced by mechanical alloying in binary systems. Materials Chemistry and Physics, Vol. 39, pp. 249-267, ISSN 0254-0584

Bakker, H.; Zhou, G.F. \& Yang, H. (1995). Mechanically driven disorder and phase transformations in alloys. Progress in Materials Science, Vol. 39, No. 3, pp. 159-241, ISSN 0079-6425

El-Eskandarany, M.S. (2001). Mechanical Alloying for Fabrication of Advanced Engineering Materials, Noyes Publications, ISBN 0-8155-1462-X, Norwich, NY

Suryanarayana, C. (2001). Mechanical alloying and milling. Progress in Materials Science, Vol. 46, No. 1-2, pp. 1-184, ISSN 0079-6425

Suryanarayana, C. (2004). Mechanical Alloying and Milling, Marcel Dekker, Inc., ISBN 0-82474103-X, New York, NY 
Zhang, D.L. (2004). Processing of advanced materials using high-energy mechanical milling. Progress in Materials Science, Vol. 49, No. 3-4, pp. 537-560, ISSN 0079-6425

Koch, C.C.; Scattergood, R.O.; Youssef, K.M.; Chan, E. \& Zhu, Y.T. (2010). Nanostructured materials by mechanical alloying: new results on property enhancement. Journal of Materials Science, Vol. 45, No. 17, pp. 4725-4732, ISSN 0022-2461

Segal, V.M.; Beyerlein, I.J.; Tome, C.N.; Chuvildeev, V.N. \& Kopylov, V.I. (2010). Fundamentals and Engineering of Severe Plastic Deformation, Nova Science Publishers, Inc., ISBN 978-1-61668-190-6, Hauppauge, NY

Fukuda, Y.; Oh-ishi, K.; Horita, Z. \& Langdon, T.G. (2002). Processing of a low-carbon steel by equal-channel angular pressing. Acta Materialia, Vol. 50, No. 6, pp. 1359-1368, ISSN 1359-6454

Perepezko, J.H.; Sieber, H.; Sagel, A. \& Fecht, H.-J. (1998). Synthesis of an amorphous Zr-Al$\mathrm{Ni}-\mathrm{Cu}$ alloy with large supercooled liquid region by cold-rolling of elemental foils. Acta Materialia, Vol. 46, No. 12, pp. 4233-4241, ISSN 1359-6454

Sauvage, X.; Dinda, G.P. \& Wilde, G. (2007). Non-equilibrium intermixing and phase transformation in severely deformed Al/Ni multilayers. Scripta Materialia, Vol. 56, No. 3, pp. 181-184, ISSN 1359-6462

Yang, D.; Hodgson, P. \& Wen, C. (2009). The kinetics of two-stage formation of $\mathrm{TiAl}_{3}$ in multilayered $\mathrm{Ti} / \mathrm{Al}$ foils prepared by accumulative roll bonding. Intermetallics, Vol. 17, No. 9, pp. 727-732, ISSN 0966-9795

Beygelzimer, Y.; Orlov, D.; Korshunov, A.; Synkov, S.; Varyukhin, V.; Vedernikova, I.; Reshetov, A.; Synkov, A.; Polyakov, L. \& Korotchenkova, I. (2006). Features of twist extrusion: Method, structures \& material properties. Solid State Phenomena, v.114, pp. 69-78, ISSN 1662-9779

Quelennec, X.; Menand, A.; Le Breton, J.M.; Pippan, R. \& Sauvage, X. (2010). Homogeneous $\mathrm{Cu}-\mathrm{Fe}$ supersaturated solid solutions prepared by severe plastic deformation. Philosophical Magazine, Vol. 90, No. 9, pp. 1179-1195, ISSN 1478-6435.

Benjamin, J.S. \& Volin, T.E. (1974). The mechanism of mechanical alloying. Metallurgical Transactions, Vol. 5, No. 8, pp. 1924-1934

Boldyrev, V.V. (2006). Mechanochemistry and mechanical activation of solids. Russian Chemical Reviews, Vol. 75, No. 3, pp. 177-189

Khina, B.B.; Solpan, I. \& Lovshenko, G.F. (2004). Modelling accelerated solid-state diffusion under the action of intensive plastic deformation. Journal of Materials Science, Vol. 39, No. 16-17, pp. 5135-5138, ISSN 0022-2461

Khina, B.B.; Lovshenko, G.F.; Konstantinov, V.M. \& Formanek, B. (2005). Mathematical model of solid-state diffusion at periodic plastic deformation. Metal Physics and Advanced Technologies, Vol. 27, No. 5, pp. 609-623, ISSN 1024-1809 (in Russian)

Khina, B.B. \& Formanek, B. (2006). Mathematical modeling of solid-state diffusion during mechanical alloying. Defect and Diffusion Forum, Vol. 249, pp. 105-110, ISSN 16629507

Maurice, D.R. \& Courtney, T.H. (1990). The physics of mechanical alloying: a first report. Metallurgical Transactions A, Vol. 21, No. 2, pp. 289-303

Magini, A. \& Iasona, A. (1995). Energy transfer in mechanical alloying (overview). Materials Transactions (JIM), Vol. 36, No. 3, pp. 123-133

Urakaev, F.Kh. \& Boldyrev, V.V. (2000a). Mechanism and kinetics of mechanochemical processes in comminuting devices: I. Theory. Powder Technology, Vol. 107, No. 1-2, pp. 93-107, ISSN 0032-5910 
Urakaev, F.Kh. \& Boldyrev, V.V. (2000b). Mechanism and kinetics of mechanochemical processes in comminuting devices: II. Applications of the theory and experiment. Powder Technology, Vol. 107, No. 3, pp. 197-206, ISSN 0032-5910

Chattopadhyay, P.P.; Manna, I.; Talapatra, S. \& Pabi, S.K. (2001). A mathematical analysis of milling mechanics in a planetary ball mill. Materials Chemistry and Physics, Vol. 68, No. 1-3, pp. 85-94, ISSN 0254-0584

Lovshenko, G.F. \& Khina, B.B. (2005). Estimation of factors influencing mechanochamical transformations during mechanical alloying in a vibratory mill. Journal of Friction and Wear, Vol. 26, No. 4, pp. 434-445 ISSN 1068-3666 (in Russian)

Lund, A.C. \& Schuh, C.A. (2004a). Molecular simulation of amorphization by mechanical alloying. Acta Materialia, Vol. 52, No. 8, pp. 2123-2132, ISSN 1359-6454

Lund, A.C. \& Schuh, C.A. (2004b). Topological and chemical arrangement of binary alloys during severe deformation. Journal of Applied Physics, Vol. 95, No. 9, pp. 4815-4822, ISSN 0021-8979

Odunuga, S.; Li, Y.; Krasnochtchekov, P.; Bellon, P. \& Averback, R.S. (2005). Forced chemical mixing in alloys driven by plastic deformation. Physical Review Letters, Vol. 95, No. 4, 045901 (4 pp.), ISSN 0031-9007

Delogu, F. \& Cocco, G. (2005). Molecular dynamics investigation on the role of sliding interfaces and friction in the formation of amorphous phases. Physical Review B, Vol. 71, No. 14, 144108 (11 pp.), ISSN 1098-0121

Butyagin, P. (2000). Mechanochemical synthesis: mechanical and chemical factors. Journal of Materials Synthesis and Processing, Vol. 8, No. 3/4, pp. 205-211, ISSN $1064-7562$

Delogu, F. \& Cocco, G. (2000). Relating single-impact events to macrokinetic features in mechanical alloying processes. Journal of Materials Synthesis and Processing, Vol. 8, No. 5/6, pp. 271-277, ISSN 1064-7562

Delogu, F.; Orru, R. \& Cao. G. (2003). A novel macrokinetic approach for mechanochemical reactions. Chemical Engineering Science, Vol. 58, No. 3-6, pp. 815-821, ISSN 0009-2509

Butyagin, P.Yu. \& Streletskii, A.N. (2005). The kinetics and energy balance of mechanochemical transformations. Physics of the Solid State, Vol. 47, No. 5, pp. 856862, ISSN 1063-7834

Schultz, R.; Trudeau, M.; Hout, J.Y. \& Van Neste, A. (1989). Interdiffusion during the formation of amorphous layers by mechanical alloying. Physical Review Letters, Vol. 62, No. 24, pp. 2849-2852, ISSN 0031-9007

Lu, L. \& Zhang, Y.F. (1999). Influence of process control agent on interdiffusion between Al and $\mathrm{Mg}$ during mechanical alloying. Journal of Alloys and Compounds, Vol. 290, No. 1-2, pp. 279-283, ISSN 0925-8388

Zhang, D.L. \& Ying, D.Y. (2001). Solid state reactions in nanometer scaled diffusion couples prepared using high energy ball milling. Materials Science and Engineering A, Vol. 301, No. 1, pp. 90-96, ISSN 0921-5093

Ma, E. (2003). Amorphization in mechanically driven material systems. Scripta Materialia, Vol. 49, No. 10, pp. 941-946, ISSN 1359-6462

Larikov, L.N.; Fal'chenko, V.M.; Mazanko, V.F.; Gurevich, S.M.; Harchenko, G.K. \& Ignatenko, A.I. (1975). Abnormal acceleration of diffusion at pulse loading of metals. Soviet Physics Doklady, Vol. 221, No. 5, pp. 1073-1075 (in Russian)

Gertsriken, D.S.; Mazanko, V.F. \& Fal'chenko, V.M. (1983). Certain regularities of atom migration in the conditions of high-strain rate plastic deformation. Metal Physics, Vol. 5, No. 4, pp. 74-90, ISSN 1024-1809 (in Russian) 
Arsenyuk, V.V.; Gertsriken, D.S.; Mazanko, V.F.; Tyshkevich, V.M. \& Fal'chenko, V.M. (2001a). Effect of defects of crystal structure on the mobility of atoms in metals at impact compression. Metal Physics and Advanced Technologies, Vol. 23, No. 7, pp. 927-937, ISSN 1024-1809(in Russian)

Arsenyuk, V.V.; Gertsriken, D.S.; Mazanko, V.F.; Tyshkevich, V.M. \& Fal'chenko, V.M. (2001b). Specific features of atom distribution in metals under pulse loading. Metal Physics and Advanced Technologies, Vol. 23, No. 9, pp. 1203-1212, ISSN 1024-1809 (in Russian)

Gertsriken, D.S.; Ignatenko, A.I.; Mazanko, V.F.; Tyshkevich, V.M. \& Fal'chenko, V.M. (1994). Specific features of interation of iron and copper with different elements at pulse deformation of metals. Metal Physics and Advanced Technologies, Vol. 16, No. 12, pp. 44-52, ISSN 1024-1809 (in Russian)

Gertsriken, D.S.; Mazanko, V.F.; Tyshkevich, V.M. \& Fal'chenko, V.M. (2001). Mass Transfer in Metals at Low Temperatures in the Conditions of External Actions, Institute of Metal Physics of the Ukrainian Academy of Sciences Publ., Kiev, Ukraine (in Russian)

Kulemin, A.V. (1978). Ultrasound and Diffusion in Metals, Metallurgiya, Moscow (in Russian)

Farber. V.M. (2002). Contribution of diffusion processes to structure formation in intense cold plastic deformation of metals. Metal Science and Heat Treatment, Vol. 44, No. 78, pp. 317-323, ISSN 0026-0673

Skakov, Yu.A. (2004). High-energy cold plastic deformation, diffusion, and mechanochemical synthesis. Metal Science and Heat Treatment, Vol. 46, No. 3-4, pp. 137-145, ISSN 0026-0673

Gapontsev, V.L. \& Koloskov, V.M. (2007). Nonequilibrium vacancy-stimulated diffusion (induced diffusion) as the main mechanism of activated alloy formation. Metal Science and Heat Treatment, Vol. 49, No. 11-12, pp. 503-513, ISSN 0026-0673

Skakov, Yu.A. (2007). Comments on the paper of V.L.Gapontsev and V.M.Koloskov "Nonequilibrium vacancy-stimulated diffusion (induced diffusion) as the main mechanism of activated alloy formation". Metal Science and Heat Treatment, Vol. 49, No. 11-12, pp. 514-516, ISSN 0026-0673

Shtremel', M.A. (2002). Participation of diffusion in the processes of mechanical alloying. Metal Science and Heat Treatment, Vol. 44, No. 7-8, pp. 324-327, ISSN 0026-0673

Shtremel', M.A. (2004). In what direction does diffusion go? (Letter to the Editor). Metal Science and Heat Treatment, Vol. 46, No. 3-4, pp. 146-147, ISSN 0026-0673

Shtremel', M.A. (2007). Review of the paper of V. L. Gapontsev and V. M. Koloskov "Nonequilibrium vacancy-stimulated diffusion (induced diffusion) as the main mechanism of activated alloy formation". Metal Science and Heat Treatment, Vol. 49, No. 11-12, pp. 517-518, ISSN 0026-0673

Lotkov, A.I.; Baturin, A.A.; Grishkov, V.N. \& Kopylov, V.I. (2007). Possible role of crystal structure defects in grain structure nanofragmentation under severe cold plastic deformation of metals and alloys. Physical Mesomechanics, Vol. 10, No. 3-4, pp. 179189

Khina, B.B. \& Froes, F.H. (1996). Modeling mechanical alloying: advances and challenges. Journal of Metals (JOM), Vol. 48, No. 7, pp. 36-38, ISSN 1047-4838

Rabkin, E. \& Estrin, Y. (1998). Pipe diffusion along curved dislocations: an application to mechanical alloying. Scripta Materialia, Vol. 39, No. 12, pp. 1731-1736, ISSN 13596462 
Mahapatra, T.K.; Das, D.; Manna, I. \& Pabi, S.K. (1998). Mathematical modelling of the mechanical alloying kinetics. Acta Materialia, Vol. 46, No. 10, pp. 3501-3510, ISSN 1359-6454

Sobolev, S.L. (1997). Local non-equilibrium transport models. Physics Uspekhi, Vol. 40, No. 10, pp. 1043-1054

Buchbinder, G.L. (2003). Mass transfer in field of fast-moving deformation disturbance. International Journal of Heat and Mass Transfer, Vol. 46, No. 19, pp. 1665-1673, ISSN 0017-9310

Bekrenev, A.N. (2002). Mass transport in metals under intensive impulse reactions. Journal of Physics and Chemistry of Solids, Vol. 63, No. 9, pp. 1627-1631, ISSN 0022-3697

Gapontsev, V.L.; Kesarev, A.G.; Kondrat'ev, V.V. \& Ermakov, A.E. (2000). Demixing of nanocrystalline alloys at generation of non-equilibrium vacancies at grain boundaries. The Physics of Metals and Metallography, Vol. 89, No. 5, pp. 8-13, ISSN 0031-918X

Gapontsev, V.L.; Kesarev, A.G. \& Kondrat'ev, V.V. (2002). Theory of diffusion phase transformation in nanocrystalline alloys at intensive plastic deformation. I. Stage of formation of concentration inhomogeneity near grain boundaries. The Physics of Metals and Metallography, Vol. 94, No. 3, pp. 5-10, ISSN 0031-918X

Gapontsev, V.L.; Razumov, I.K. \& Gornostyrev, Yu.N. (2003). Theory of diffusion phase transformation in nanocrystalline alloys at intensive plastic deformation. II. Demixing of ideal solid solutions. The Physics of Metals and Metallography, Vol. 96, No. 4, pp. 5-15, ISSN 0031-918X

El-Eskandarany, M.S.; Akoi, K.; Sumiyama, K. \& Suzuki, K. (1997). Cyclic crystallineamorphous transformations of mechanically alloyed $\mathrm{C}_{75} \mathrm{Ti}_{25}$. Applied Physics Letters, Vol. 70, No. 13, pp. 1679-1681, ISSN 0003-6951

Courtney, T.H. \& Lee, J.K. (2005). Cyclical phase transformations and dynamic equilibrium in mechanical alloying. Philosophical Magazine, Vol. 85, No. 2-3, pp. 153-170, ISSN 1478-6435

Kaibyshev, O.A. (2002). Fundamental aspects of superplastic deformation. Materials Science and Engineering A, Vol. 324, No. 1-2, pp. 96-102, ISSN 0921-5093

Wu, X.-L. \& Ma, E. (2006). Dislocations in nanocrystalline grains. Applied Physics Letters, Vol. 88, No. 23, 231911 (3 pp.), ISSN 0003-6951

Foct, J. (2004). An attempt to extract common behaviour from heterogeneous results about mechanical alloying. Journal of Materials Science, Vol. 39, No. 16-17, pp. 5011-5017, ISSN 0022-2461

Raabe, D.; Ohsaki, S. \& Hono, K. (2009). Mechanical alloying and amorphization in Cu-Nb$\mathrm{Ag}$ in situ composite wires studied by TEM and atom probe tomography. Acta Materialia, Vol. 57, No. 17, 5254-5263, ISSN 1359-6454

Quelennec, X.; Menand, A.; Le Breton, J.M.; Pippan, R. \& Sauvage, X. (2010). Homogeneous $\mathrm{Cu}-\mathrm{Fe}$ supersaturated solid solutions prepared by severe plastic deformation. Philosophical Magazine, Vol. 90, No. 9, pp. 1179-1195, ISSN 1478-6435

Bellon, P. \& Averback, R.S. (1995). Nonequilibrium roughening of interfaces in crystals under shear: application to ball milling. Physical Review Letters, Vol. 74, No. 10, pp. 1819-1822, ISSN 0031-9007

Meyers, M.A. \& Chawla, K.K. (2009). Mechanical Behavior of Materials, Cambridge University Press, ISBN 978-0-521-86675-0, Cambridge, UK 
Argon, A. (2008). Strengthening Mechanisms in Crystal Plasticity, Oxford University Press, ISBN 978-0-19-851600-2, Oxford, UK

Gutkin, M.Yu.; Ovid'ko, I.A. \& Pande, C.S. (2001). Theoretical models of plastic deformation processes in nanocrystalline materials. Reviews on Advanced Materials Science, Vol. 2, pp. 80

Bobylev, S.V.; Mukherjee, A.K. \& Ovid'ko, I.A. (2009). Transition from plastic shear into rotation deformation mode in nanocrystalline metals and ceramics. Reviews on Advanced Materials Science, Vol. 19, No1-2, pp. 103-113

Gutkin, M.Yu.; Ovid'ko, I.A. \& Skiba, N.V. (2005). Emission of partial dislocations from triple junctions of grain boundaries in nanocrystalline materials. Journal of Physics D: Applied Physics, Vol. 38, No. 21, pp. 3921-3925, ISSN 0022-3727

Levitin, V. (2006). High Temperature Strain of Metals and Alloys: Physical Fundamentals, WileyVCH, ISBN: 3-527-31338-9, Weinheim

Wang, J.; Hoagland, R.G.; Hirth, J.P. \& Misra, A. (2008). Atomistic modeling of the interaction of glide dislocations with "weak" interfaces. Acta Materialia, Vol. 56, No. 19, pp. 5685-5693, ISSN 1359-6454

Khusid, B.M. \& Khina, B.B. (1991). Kinetic model for intermetallic compound formation during interdiffusion in a binary system. Physical Review B, Vol. 44, No. 19, pp. 10778-10793, ISSN 1098-0121

Desre, P.J. \& Yavari, A.R. (1990). Suppression of crystal nucleation in amorphous layers with sharp concentration gradients. Physical Review Letters, Vol. 64, No. 13, pp. 15331536, ISSN 0031-9007

Desre, P.J. (1991). Effect of sharp concentration gradients on the stability of a twocomponent amorphous layer obtained by solid state reaction. Acta Metallurgica et Materialia, Vol. 39, No. 10, pp. 2309-2315, ISSN 1359-6454

Gusak, A.M.; Hodaj, F. \& Bogatyrev, A.O. (2001). Kinetics of nucleation in the concentration gradient. Journal of Physics: Condensed Matter, Vol. 13, No. 12, pp. 2767-2787, ISSN 0953-8984

Bullough, R.; Eyre, B.L. \& Krishan, K. (1975). Cascade damage effects on the swelling of irradiated materials. Proceedings of the Royal Society of London, Vol. A346, No. 1644, pp. $81-102$

Murphy, S.M. (1987). Spatial instability in dislocation structure under irradiation. Europhysics Letters, Vol. 3, No. 12, pp. 1267-1272

Mansur, L.K. (1979). Effect of point defect trapping and solute segregation on radiationinduced sweeling and creep. Journal of Nuclear Materials, Vol. 83, pp. 109-127, ISSN 0022-3115

Gusak, A.M. \& Bushin, I.N. (1996). Modeling the motion of point defects in the shock wave front. Metal Physics, Vol. 18, No. 9, pp. 68-72, ISSN 1024-1809 (in Russian)

Nabarro, F.R.N.; Basinski, Z.S. \& Holt, D.B. (1964). The plasticity of pure single crystals. Advances in Physics, Vol. 50, pp. 193-323

Novikov, I.I. (1983). Defects of Crystal Structure in Metals, Metallurgiya, Moscow (in Russian)

Hirth, J.P. \& Lothe, J. (1982). Theory of Dislocations, second Edition, John Wiley \& Sons, Inc., New York, NY

Vo, N.Q.; Averback, R.S.; Bellon, P.; Odunuga, S. \& Caro, A. (2008). Quantitative description of plastic deformation in nanocrystalline $\mathrm{Cu}$ : Dislocation glide versus grain boundary sliding. Physical Review B, Vol. 77, No. 13, 134108 (9 pp.), ISSN 1098-0121 
Gurao, N.P. \& Suwas, S. (2009). Deformation mechanisms during large strain deformation of nanocrystalline nickel. Applied Physics Letters, Vol. 94, No. 19, 191902 (3 pp.), ISSN 0003-6951

Voroshnin, L.G. \& Khusid, B.M. (1979). Diffusion Mass Transfer in Multicomponent Systems, Nauka i Tehnika Publ., Minsk, Belarus (in Russian)

Adda, Y. \& Philibert, J. (1966). Diffusion in Solids, Presses Universitaires de France, Paris, Vol. 1 (in French)

Gurov, K.P.; Kartashkin, B.A. \& Ugaste, U.E. (1981). Mutual Diffusion in Multiphase Metallic Systems. Nauka, Moscow (in Russian)

Kosevich, V.M.; Ievlev, V.M.; Palatnik, L.S. \& Fedorenko, A.I. (1980). Structure of Intercrystalline and Interphase Boundaries, Metallurgiya, Moscow (in Russian)

Kalitkin, N.N. (1978). Numerical Methods, Nauka, Moscow (in Russian)

Brandes, E.A. \& Brook, G.B. (Ed.) (1992). Smithells Metals Reference Book, seventh edition, Butterworth-Heinemann, ISBN 075063624 6, Oxford, UK

Bokshtein, B.S. (1978). Diffusion in Metals, Metallurgiya, Moscow (in Russian)

Mishin, Y. (2001). 50 years of grain boundary diffusion: what do we know about it today? Defect and Diffusion Forum, Vol. 194-199, pp. 1113-1126, ISSN 1662-9507

Cherdyntsev, V.V. \& Kaloshkin, S.D. (2010). On the kinetics of phase and structural transformations upon mechanical alloying. The Physics of Metals and Metallography, Vol. 109, No. 5, pp. 492-504, ISSN 0031-918X

Ungar, T.; Schafler, E.; Hanak, P.; Bernstorff, S. \& Zehetbauer, M. (2007). Vacancy production during plastic deformation in copper determined by in situ X-ray diffraction. Materials Science and Engineering A, 2007, Vol. 462, No. 1-2, pp. 398-401, ISSN 0921-5093

Popov, L.E.; Starenchenko, V.A. \& Shalygin, I.I. (1990). Intensity of point defect generation at plastic deformation. The Physics of Metals and Metallography, No. 6, pp. 31-36, ISSN 0031-918X

Fecht, H.J. (1992). Defect-induced melting and solid-state amorphization. Nature, Vol. 356, No. 6365, pp. 133-135, ISSN 0028-0836. 


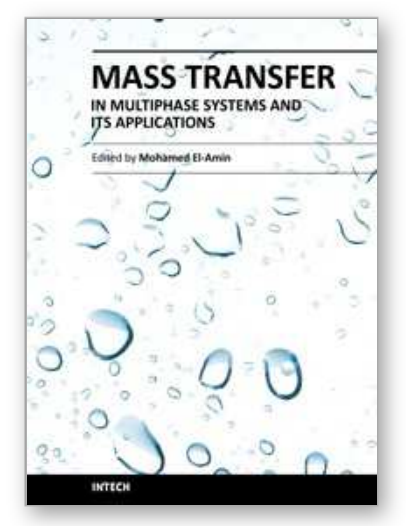

\author{
Mass Transfer in Multiphase Systems and its Applications \\ Edited by Prof. Mohamed El-Amin
}

ISBN 978-953-307-215-9

Hard cover, 780 pages

Publisher InTech

Published online 11, February, 2011

Published in print edition February, 2011

This book covers a number of developing topics in mass transfer processes in multiphase systems for a variety of applications. The book effectively blends theoretical, numerical, modeling and experimental aspects of mass transfer in multiphase systems that are usually encountered in many research areas such as chemical, reactor, environmental and petroleum engineering. From biological and chemical reactors to paper and wood industry and all the way to thin film, the 31 chapters of this book serve as an important reference for any researcher or engineer working in the field of mass transfer and related topics.

\title{
How to reference
}

In order to correctly reference this scholarly work, feel free to copy and paste the following:

Boris B. Khina and Grigoriy F. Lovshenko (2011). Modeling Enhanced Diffusion Mass Transfer in Metals during Mechanical Alloying, Mass Transfer in Multiphase Systems and its Applications, Prof. Mohamed El-Amin (Ed.), ISBN: 978-953-307-215-9, InTech, Available from: http://www.intechopen.com/books/mass-transfer-inmultiphase-systems-and-its-applications/modeling-enhanced-diffusion-mass-transfer-in-metals-duringmechanical-alloying

\section{INTECH}

open science | open minds

\section{InTech Europe}

University Campus STeP Ri

Slavka Krautzeka 83/A

51000 Rijeka, Croatia

Phone: +385 (51) 770447

Fax: +385 (51) 686166

www.intechopen.com

\section{InTech China}

Unit 405, Office Block, Hotel Equatorial Shanghai

No.65, Yan An Road (West), Shanghai, 200040, China

中国上海市延安西路65号上海国际贵都大饭店办公楼405单元

Phone: +86-21-62489820

Fax: $+86-21-62489821$ 
(C) 2011 The Author(s). Licensee IntechOpen. This chapter is distributed under the terms of the Creative Commons Attribution-NonCommercialShareAlike-3.0 License, which permits use, distribution and reproduction for non-commercial purposes, provided the original is properly cited and derivative works building on this content are distributed under the same license. 